\title{
Quality of death in the river buffalo (Bubalus bubalis)
}

\author{
Daniel Mota-Rojas $^{\text {a* }}$ (D) | Marcelo Daniel Ghezzi ${ }^{b}$ | Fabio Napolitanoc ${ }^{(D)}$ | Marcelo Rosmini ${ }^{d}$ | \\ Isabel Guerrero-Legarreta ${ }^{(D)}$ | Julio Martínez-Burnes ${ }^{f}$ (D) Karina Lezama-García | Agatha \\ Miranda-Cortés $^{\mathrm{g}}$ | Leonardo Thielo de la Vega ${ }^{\mathrm{h}, \mathrm{i}}$ | Patricia Mora-Medina ${ }^{\mathrm{i}}$ | Ismael Hernández-
}

Ávalos

aNeurophysiology, Behavior and Animal Welfare Assessment, DPAA. Universidad Autónoma Metropolitana (UAM), Mexico City, Mexico.

Animal Welfare Area, Faculty of Veterinary Sciences (FCV). Universidad Nacional del Centro de la Provincia de Buenos Aires (UNCPBA), Argentina.

Scuola di Scienze Agrarie, Forestali, Alimentari ed Ambientali, Università degli Studi della Basilicata, Potenza, Italy.

Department of Public Health, Faculty of Veterinary Science, National University of Litoral, Esperanza, Argentina.

Universidad Autónoma Metropolitana (UAM) Iztapalapa Campus, Department of Biotechnology, Mexico City, Mexico.

Graduate and Research Department, Facultad de Medicina Veterinaria y Zootecnia, Universidad Autónoma de Tamaulipas, Victoria City, Tamaulipas, Mexico.

Clinical Pharmacology and Veterinary Anaesthesia. Department of Biological Science. FESC. Universidad Nacional Autónoma de México (UNAM), Mexico.

Comissão de Bem-Estar Animal da Associação Brasileira de Proteína Animal (ABPA), São Paulo, Brazil.

Animal Welfare and Food Safety, F\&S Consulting, Dublin, Ireland.

Department of Livestock Sciences. Universidad Nacional Autónoma de México (UNAM), FESC. Mexico.

*Corresponding author: dmota100@yahoo.com.mx

Abstract Results on appropriate, inappropriate, and painful slaughtering methods of river buffalo (Bubalus bubalis) are discussed. Undesirable consequences of poor desensitization and/or slaughtering procedures, causing pain and suffering to animals, are also approached. These considerations are relevant as unsuitable methods can reduce consumer acceptance and commercial value of the meat obtained from animals undergoing deficient slaughtering procedures due to a lack of concern regarding their welfare. Relevant databases -Scopus, Science Direct, and PubMed-were searched for this review, including keywords such as pain, slaughter, stunning, Bubalus bubalis, and animal welfare. A detailed description of river buffalo's encephalic anatomy was compared to cattle concerning correct stunning and slaughter methods. The neurobiological processes of pain felt by animals when inadequately desensitized was also examined. Finally, recent findings on stunning methods for buffaloes were discussed, including encephalography. It was concluded that different animal species may require different stunning methods; at the same, time the optimal anatomical site also varies between species. Therefore, it is of the utmost importance to train the personnel performing these procedures (transport, stunning, slaughtering) to avoid mishandling that jeopardizes animal welfare by generating stimuli that trigger neurophysiological responses and, in turn, translate into pain during slaughter and reduced meat quality.

Keywords abattoir, buffalo welfare, humane slaughter, nociception, pain, stunning

\section{Introduction}

Slaughtering of river buffaloes (Bubalus bubalis) to obtain edible meat is becoming popular in Africa, India, and Southeast Asia, mainly in Muslim communities, and other countries throughout the planet. The main reason spreading is the ever-increasing demand for meat products (Gibson et al 2015a). Although meat and carcass yields are lower in buffaloes than in cattle (e.g. Lapitan et al., 2007), the meat of this species has numerous advantages over beef in terms of meat quality (Kandeepan et al 2013), such as lower cholesterol and saturated fat levels (Irurueta et al 2008), intense red color that attracts the consumer, and higher tenderness (Spanghero et al 2004; Guerrero-Legarreta et al 2019; 2020). Moreover, buffaloes yield higher percentages of meat for butchering; therefore, they can provide a better return on investment than domestic cattle.

There is, however, a factor that can diminish these advantages, namely, the stress that animals experience at the time of slaughter due primarily to pain and fear (Mota-Rojas et al 2010a,b; 2016). In this regard, all the supply chain personnel must understand that river buffaloes and cattle (Bos taurus) present significant anatomical differences that must be taken into account when choosing optimal stunning and slaughter procedures to ensure adequate quality of death for each species. The goal of slaughtering techniques is to prevent, by all possible means, fear, stress, and pain in the animals (Mota-Rojas et al 2012; 2019a,b). Achieving this requires two steps: stunning to produce a loss of consciousness and death by exsanguination. When performed correctly, stunning renders the animal unconscious and insensitive to environmental stimuli because its brain is incapable of processing sensory information (Farouk 2013; Terlouw et al 2016). In addition, adequate stunning is also important in guaranteeing meat quality and food safety (Fike and Spire 2006; Mota-Rojas et al 2010a,b; 2016).

This review aims to present the state of the art on the slaughter methods used in river buffalo. It also discusses the consequences of poor desensitization and painful slaughter in 
relation to quality of death, animal welfare, and meat quality in this species.

\section{Cephalic anatomy: key differences between river buffalo and bovines of the genus Bos}

A study by Alsafy et al (2013) used computed tomography (CT) to compare skulls of Egyptian buffaloes (Bubalus bubalis) and cattle (Bos taurus). This technique allows for identifying significant differences in the cranial anatomy of these two species. The first distinction the authors observed was the form of septa of paranasal sinuses, which are in contact with the floor of the nasal cavity in buffaloes. The second observed feature was that buffaloes possess two vomeronasal organs, one on each side of the septum. In contrast, in cattle, the septa do not extend to the nasal cavity floor but form a central channel that ends at the nasopharynx. Figures $1 \mathrm{~A}$ and $1 \mathrm{~B}$ illustrate these substantial differences between the skulls of the two species.
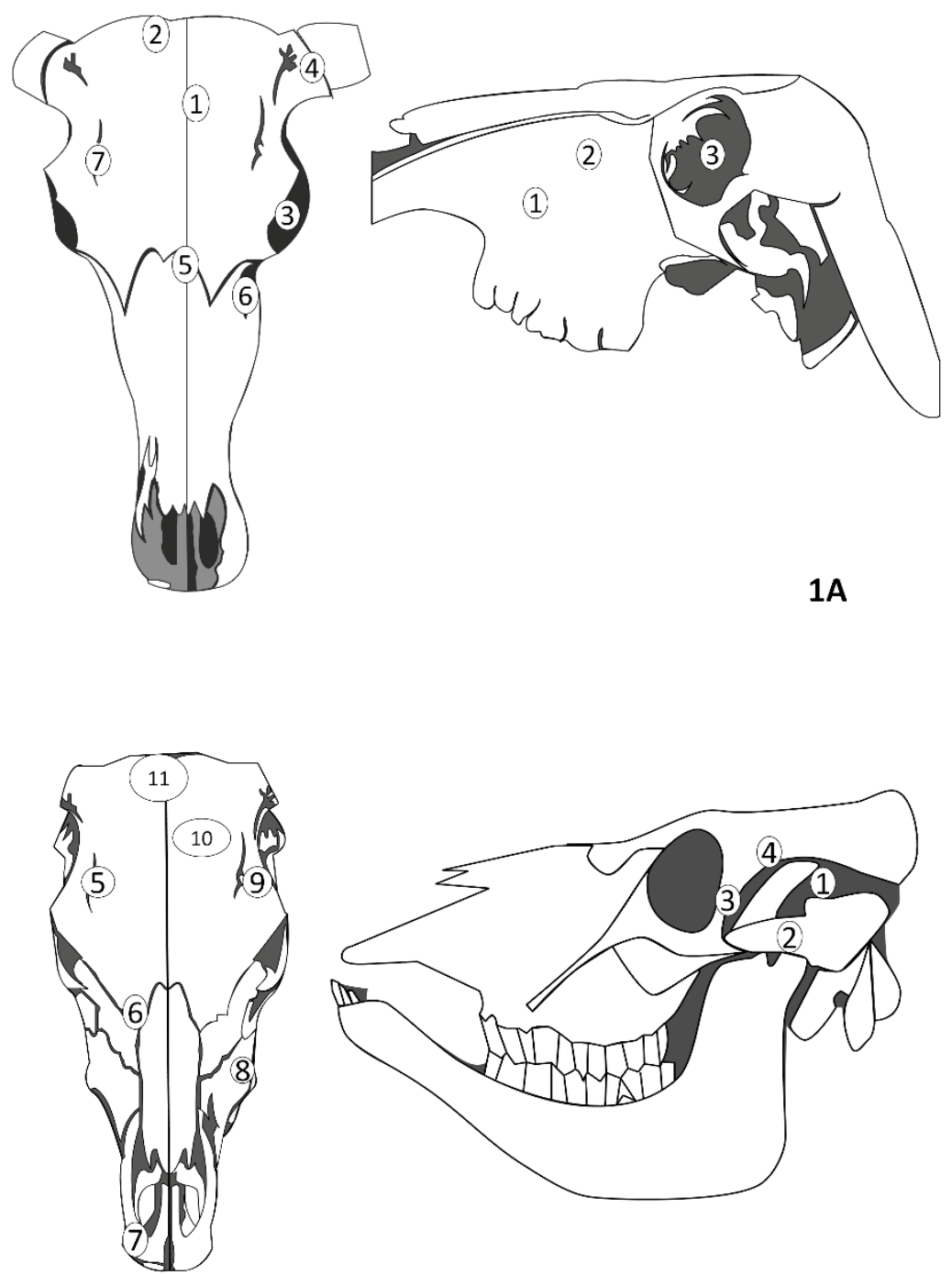

1B

Figure $1 \mathrm{~A}$. Frontal and lateral view of Bubalus bubalis skull: 1. frontal bone; 2. parietal bone; 3. orbit; 4 . cornual process of the frontal bone; 5 . nasal bone; 6. lacrimal bone; 7. supraorbital canal. B. Frontal and lateral view of a cattle skull: 1 . temporal canal; 2 . zygomatic arch; 3 . frontal process of the zygomatic arch; 4. temporal line of the frontal bone; 5. supraorbital canal; 6. fontanelle; 7. premaxillae; 8 . facial canal; 9 . temporal line; 10 . frontal bone; 11. intercornual bulge. Certain features of river buffalo head-broad frontal sinuses, hard bony plates, thicker hide- prevent the 90 -mm captive bolt gun from effectively impacting the cranial cavity. Even larger caliber captive bolt guns (up to $180 \mathrm{~mm}$ ) may not be efficacious in inducing loss of consciousness in river buffaloes.

\section{Importance of effective stunning}

The primary goal of all slaughtering procedures should be to ensure that animals do not suffer unnecessary pain. The above requires adapting the ideal stunning technique for each species before slaughter as the only way to guarantee that the animals remain unconscious and totally desensitized throughout the process. Only in this way, good quality of 
death can be achieved, as it is marked by the absence of pain (Gibson et al 2015a,b). When stunning is performed inadequately, slaughtering will diminish animal welfare by inflicting intense pain, a condition that may deteriorate the quality of the meat (Johnson et al 2012; Shearer 2018).

A schematic representation in Figure 2A shows the ocular reflex triggered by shining a beam of light on the retina to activate cranial pairs II -optic nerve (afferent pathway)and III, the oculomotor nerve (efferent pathway), as well as the eye muscles. This reflex is of little value during the processes of stunning and exsanguination because only a small amount of blood reaches the retina in this period. In contrast, pupillary dilatation in contrast is recognized as a reliable sign of total cerebral disfunction that can occur in animals that have been paralyzed but maintain consciousness - also, the no reflex response to pricking and pinching (B). Therefore, reflexes that respond to painful stimuli, in turn, are accurate indicators of conscious vs. unconscious states in animals after applying any stunning method.

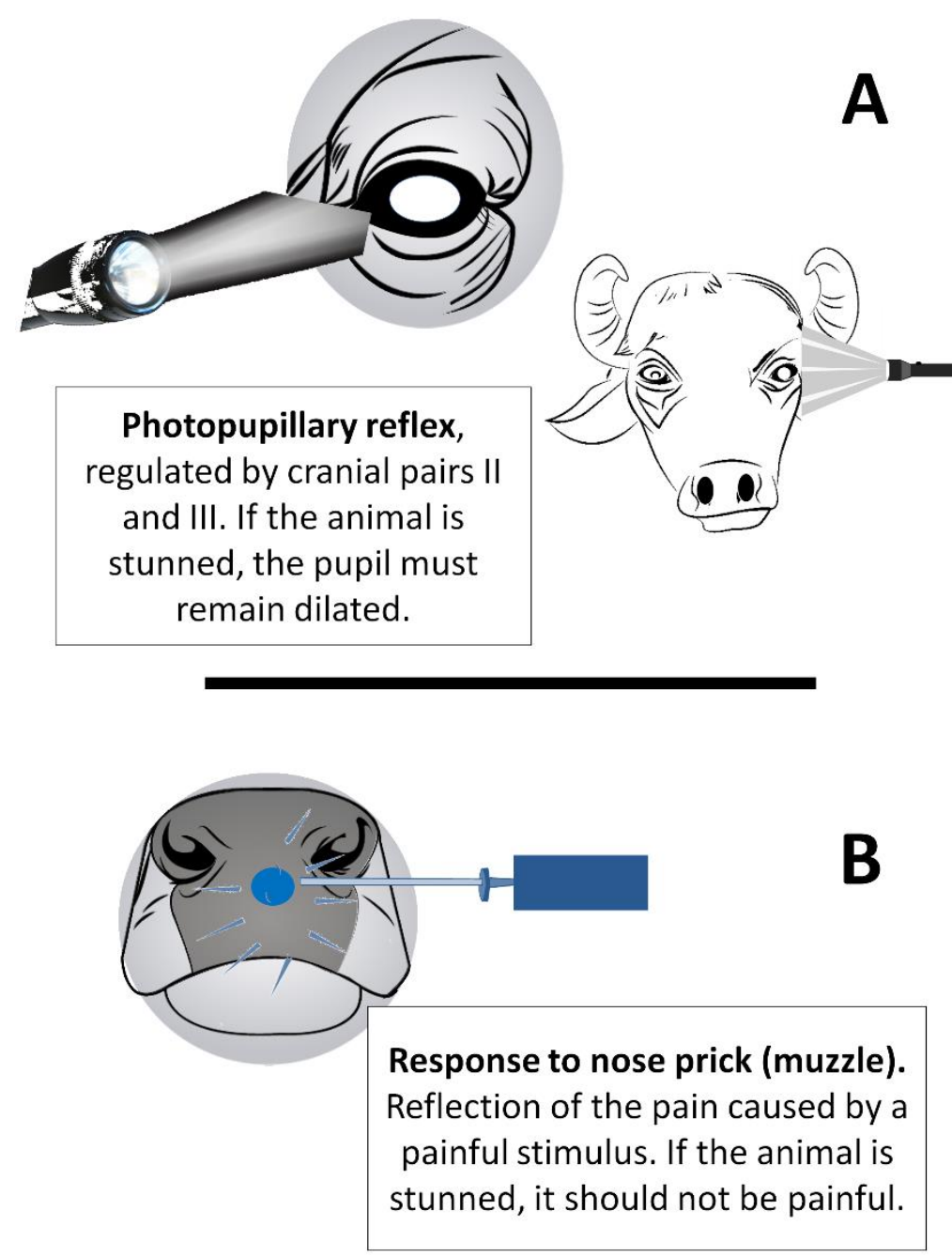

Figure 2 Reflexes of the return to sensitivity in large ruminants.

\subsection{Neurobiology of pain}

During exsanguination, an extended, deep cut is made through the animal's neck's soft tissues of the neck to sever the main blood vessels (carotid arteries, jugular veins, trunk of the brainstem). Since this area of the neck contains a wide variety of nociceptive fibers that generate a cascade of sensory impulses (Imlan et al 2020), the cut effectively interrupts the brain supply of nutrients and oxygen, inducing death by hypovolemic shock (Robins et al 2014). However, if the cutting of the major blood vessels to allow bleeding is done after ineffective stunning (desensitization), the animal feels acute pain because many neck structures (connective tissue, skin, veins, arteries, muscles) contain physiological sensors called nociceptors, the sensors that send electrical impulses to the central nervous system (SNC), where the impulses are detected and identified as pain (Johnson et al 2015). It is essential to understand how, under these conditions, the pain stimulus can travel through an animal's body until it is perceived and interpreted in the cerebral cortex. 
The physiopathological mechanisms of nociception involved in the neurophysiological process of pain are alike among any mammal species. Observations suggest that animals and humans use the same neuronal process to recognize, conduct, and modulate pain through a series of neurons, following three pathways (Hernandez-Avalos et al 2019). In sequential order, the mechanisms involved are transduction, transmission, modulation, projection, and perception (see Figure 3 ). In the first step of the so-called nociceptive arch, primary (first-order) afferent neurons in the nociceptors convert the nociceptive stimulus into an electrical signal that changes the permeability of the membrane of the receptor and alters its state of repose (Muir 2009). Ellison (2017) showed that harmful chemical, mechanical, or thermal stimuli could be perceived by muscles, viscera, bones, or the skin and transformed into electrical impulses. Once this takes place, the noxious stimulus triggers the opening of sodium, potassium, and calcium ion channels where electrical impulses are produced and then travel along neuronal axons to carry the nociceptive signal to the spinal cord, brainstem, thalamus, and cortex (Dinakar and Stillman 2016), where the perception or recognition of pain occurs (Terlouw et al 2016; Ellison 2017; Glardon et al 2018; Lopes et al 2019).

The damage inflicted at the tissue level releases chemical substances with allogenic capacity into the immediate environment of the peripheral sensory terminations sensitizing (activating) nociceptors. These chemical mediators include ions $\left(\mathrm{H}^{+}, \mathrm{K}^{++}\right)$, bradykinin, prostaglandin, leukotrienes, serotonin, histamine, substance $\mathrm{P}$, thromboxanes, platelet-activating factor, reactive oxygen species (ROS) and cytokines like interleukins, tumor necrosis factor (TNF), and neurotrophins, all of which are produced during the nociceptive event. Some of these agents can activate the polymodal c fibers or generate the sensitization of receptors, thus aggravating the sensation of pain (Hassel and Dingledine 2012; De Oliveira et al 2016).

Step two -transmission- is understood as the conduction of an electrical signal generated in the nociceptors along the axons of first-order neurons that form a synapse with the second-order neurons in the dorsal horn of the spinal cord. The information is relayed through two primary afferent nociceptive neurons, namely, the polymodal c fibers, or $\mathrm{C}$ polymodal nociceptors that, as described above, transmit chemical, thermal, and mechanical nociceptive information. Because $A \delta$ fibers respond to high-intensity mechanical stimuli, these are called high-threshold mechanoreceptors (Muir 2009). In ascending order, the main corporal structures involved at this level are the spinal cord, brainstem, and thalamus, but the spinal cord has the most extensive participation. The spinal cord is organized in two dorsal horns, two ventral horns, and an intermediate portion, a structure that allows it to act as an information relay station located between the periphery and the higher centers. Its functions include integrating and controlling nociceptive stimuli (Zegarra 2007; Bosmans et al 2009; Cooley 2015). Here, it is possible to distinguish the neurons that process specific, high-threshold, nociceptive information from those that process both high- and low-threshold information (unspecific nociceptors). The latter are called neurons of a wide dynamic range (NWDR) (Reyes et al 2004; Covarrubias, 2013; Walters, 2018).

In general terms, the Rexed laminae I, II, and $\mathrm{V}$ in the dorsal horn receive the nociceptive information, while the others receive non-nociceptive information from innocuous stimuli (AB fibers). These neurons, classified as NWDR, function in proportion to the degree of stimulation they receive, so a mild stimulus causes them to discharge their potentials with greater frequency, while intense stimulation produces the opposite result (Bosmans et al 2009; Bourne et al 2014; Sneddon et al 2014).

Three types of second-order neurons are found in the dorsal horn. The projecting neurons are responsible for carrying the spinal cord's sensation to the superior brain centers, or third-order neurons (Bourne et al 2014). The propriospinal neurons that extend along various spine segments are in charge of the reflexes associated with nociception. Finally, the interneurons perform modulation of the transmission of the pain signals (Bosmans et al 2009).

The next step in the process is modulation, which operates through inhibitory or excitatory mechanisms that alter the nervous impulses' transmission. This mechanism represents all the changes that occur in the stimulusresponse process through post-transitional modifications of the excitability of the neurons that, in turn, results in functional alterations of the ion channels on the cell surface of the primary neurons and the dorsal horn, where glutamate and aspartate excitatory neurotransmitters participate. However, at this level, there may also be participation by catecholamines, prostaglandins, prostacyclins, bradykinin, substance $P$ (a peptide related to the calcitonin gene), interleukins, and leukotrienes. When hyperalgesia or allodynia responses are generated, these can relate their nociceptive action to NMDA, AMPA, and Kainato receptors also mediated by ion channels. At this point $\mathrm{Na}^{2+}, \mathrm{K}^{2+}, \mathrm{Ca}^{2+}$ and $\mathrm{Mg}^{2+}$ intervene (Lamont et al 2000; Leung, 2015; Hernández-Ávalos et al 2019).

When harmful stimulus, in this case, poor stunning, is carried ascendingly, the secondary (projection or secondorder) neurons receive the information from the primary neurons and carry it to such superior brain centers as the oblong medulla, bridge, midbrain, thalamus, and hypothalamus. From there, the nociceptive information is transported to the brain through nerve tracts that originate in the laminae of the dorsal horn (Muir 2009; McKune et al 2015). The spinothalamic beam is the most important primary nociceptive pathway. It is located anterolaterally in the spinal cord's white matter and runs from laminae I and IV towards lamina VIII. This structure contains axons of both specific nociceptive and NWDR neurons. It is divided into neospinothalamic (lateral) and paleospinothalamic (medial) sections. The former is the primary pathway for acute pain and is in charge of identifying the stimulus's location, intensity, and duration. In turn, the latter transmits slow or 
chronic pain, together with the unpleasant emotional perception of pain. The main neurotransmitter here is substance $P$ (Bourne et al 2014; Dong-Ho et al 2017).

The final stage -perception- consists in processing, integrating, and recognizing the information that reaches the thalamus and cerebral cortex. In those centers, supraspinal (third-order) neurons integrate the signals from the spinal neurons and project them to cortical and subcortical areas in a process that culminates with integrating all the information to produce the emotional, conscious experience of pain
(Lorenz et al 2011; Landa 2012). Because this develops at the sensory cortex, it participates in generating affective and behavioral outputs that may be manifested as anxiety, fear, aggression, or depression, but it also aids in developing autonomous reactions at the visceral and endocrine levels. Altogether, these events modulate an animal's motor responses to inefficient desensitization, which may include such phenomena as attacks, efforts to flee, or exacerbated reflexes (Kopf and Patel 2010; Kata et al 2015).

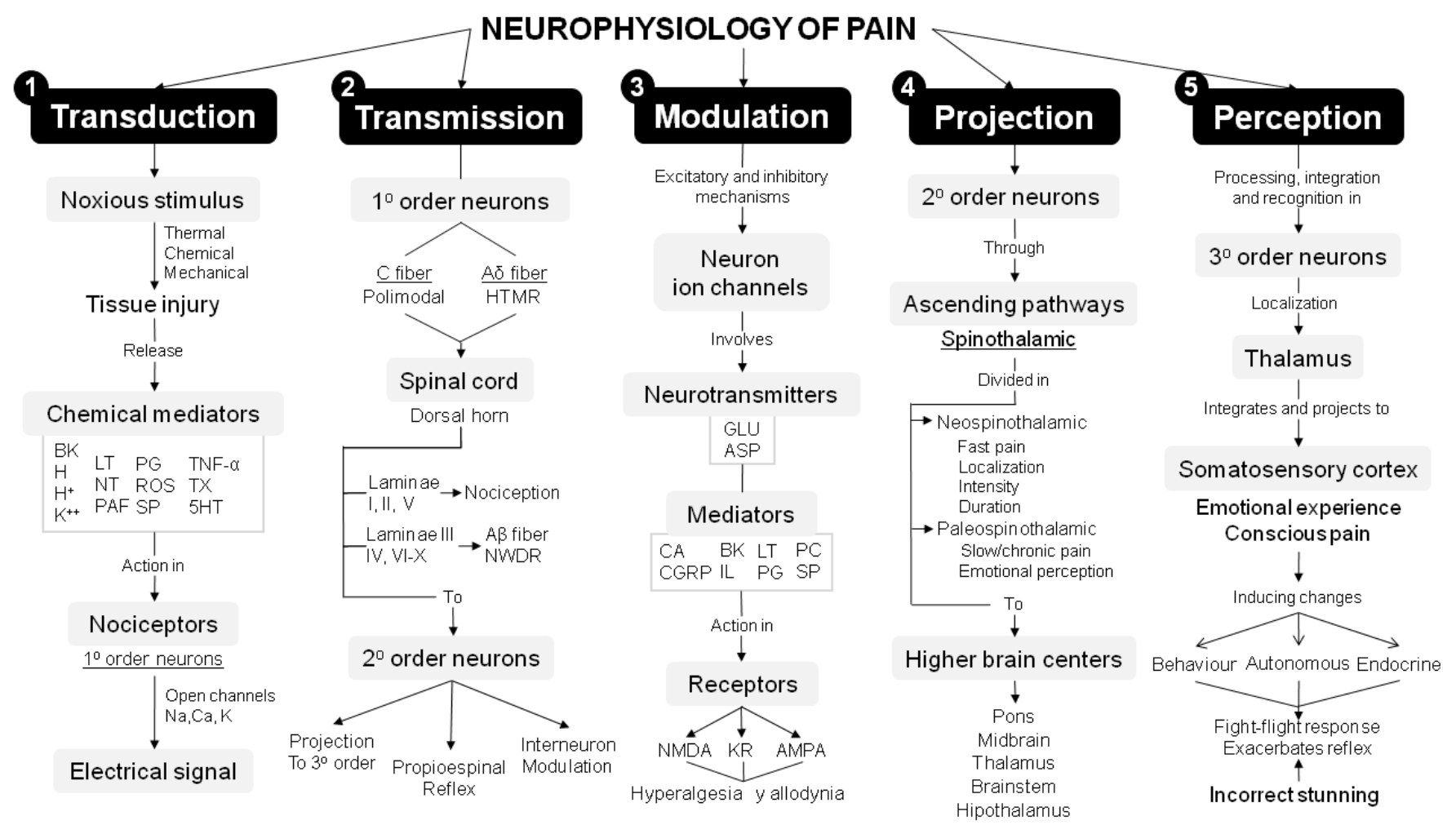

Figure 3 Processes and steps involved in pain neurobiology (Bosmans et al 2009; Bourne et al 2014; Dong-Ho et al 2017; Hernandez-Avalos et al 2019). Abbreviations: ASP: aspartate; BK: bradykinin; CA: catecholamines; CGRP: calcitonin gene-related peptide; GLU: glutamate; H: histamine; HTMR: highthreshold mechanoreceptors; IL: interleukin; KR: kainate receptor; LT: leukotrienes; NT: neurotrophins; PAF: platelet-activating factor; PC: prostacyclin; PG: prostaglandin; ROS: free radicals; SP: substance P; TNF: tumoral necrosis factor; TX: thromboxanes; 5 HT: serotonin.

\subsection{Meat quality}

When adequately performed, stunning facilitates exsanguination and improves the quality of the meat obtained from the slaughtered animal (Mota-Rojas et al $2010 a, b)$. The above has led to a greater understanding of the importance of conducting this operation with great precision. Cutting the animal's neck quickly and effectively requires an extremely sharp knife (Imlan et al 2020); an inadequate cut can generate elevated levels of glucocorticoids and catecholamines, two substances that affect the postmortem glycolytic potential and increase the $\mathrm{pH}$ of the meat (MotaRojas et al., 2010a,b; Teke et al 2014; Mota-Rojas et al., 2012; 2016). Under these conditions, an animal's muscular preslaughter glycogen reserve significantly decreases, altering meat $\mathrm{pH}$ and negatively affecting tenderness, aging potential, color, and water retention capacity (Gregory 2003). Normal glycogen levels in cattle and sheep range from 75-120 $\mathrm{mmol} / \mathrm{kg}$ (Immonen et al 2000; Ferguson and Warner 2008), while meat $\mathrm{pH}$ should be in the 5.5-5.6 range (Tarrant 1990).

It is also essential to understand the potential effect of stunning techniques on meat quality, because not only it may trigger an increase in catecholamine and glucocorticoid levels in the animal -as outlined above- but since meat can contaminate under inadequate stunning conditions. Experiments with sheep raised for meat production were conducted to determine whether stunning by a hidden plunger gun results in internal or external microbial contamination (Anil et al 2002; Anil and Austin, 2003). The animals were inoculated in the brain with a marker organism, E. coli $\mathrm{K} 12$ or Pseudomonas fluorescens, immediately after impact through the wound inflicted by stunning. The marker organisms were later detected in the animal blood, lungs, spleen, lymph nodes, deep muscle, and the canal. When the captive bolt gun method was applied to consecutive stuns, followed by cerebral inoculation, the marker organisms 
introduced were detected in $30 \%$ of the animals and on the surface of $40 \%$ of their meat. These findings concluded that the pneumatically-operated or conventional cartridgeoperated penetrating captive bolt guns, customarily used to stun animals for human consumption, may carry risks of internal and/or external contamination of edible tissues and organs. This is not only sheep's case; similar results have been obtained using these markers in cattle (Anil et al 2002; Anil and Austin 2003).

\section{Recent findings on the stunning of the river buffalo}

\subsection{Encephalography}

Recent work conducted to evaluate desensitization or unconsciousness sustains that electroencephalography (EEG) can be a useful tool because pronounced changes are observable in EEGs immediately after the stunning impact, most markedly in the delta and theta waves, which tend to become isoelectric lines. Unconsciousness in animals is assumed by analogy with similarities in EEG studies in humans (EFSA 2004). EEG recordings in animals show relatively small waves that increase their amplitude during the tonic phase and reduce their frequency in the clonic phase, resulting in a period of decreased electrical activity (Figure 4), as studies with pigs, sheep, and cows have demonstrated (Lambooy 1982; Anil and McKinstry 1992). In contrast, an animal that presents alpha and beta waves is still considered a state of consciousness (Kooi et al 1978). This evidence suggests that the EEG technique is another approach that helps in evaluating stunning quality, though its feasibility is limited by costs involved and training required to interpret results.

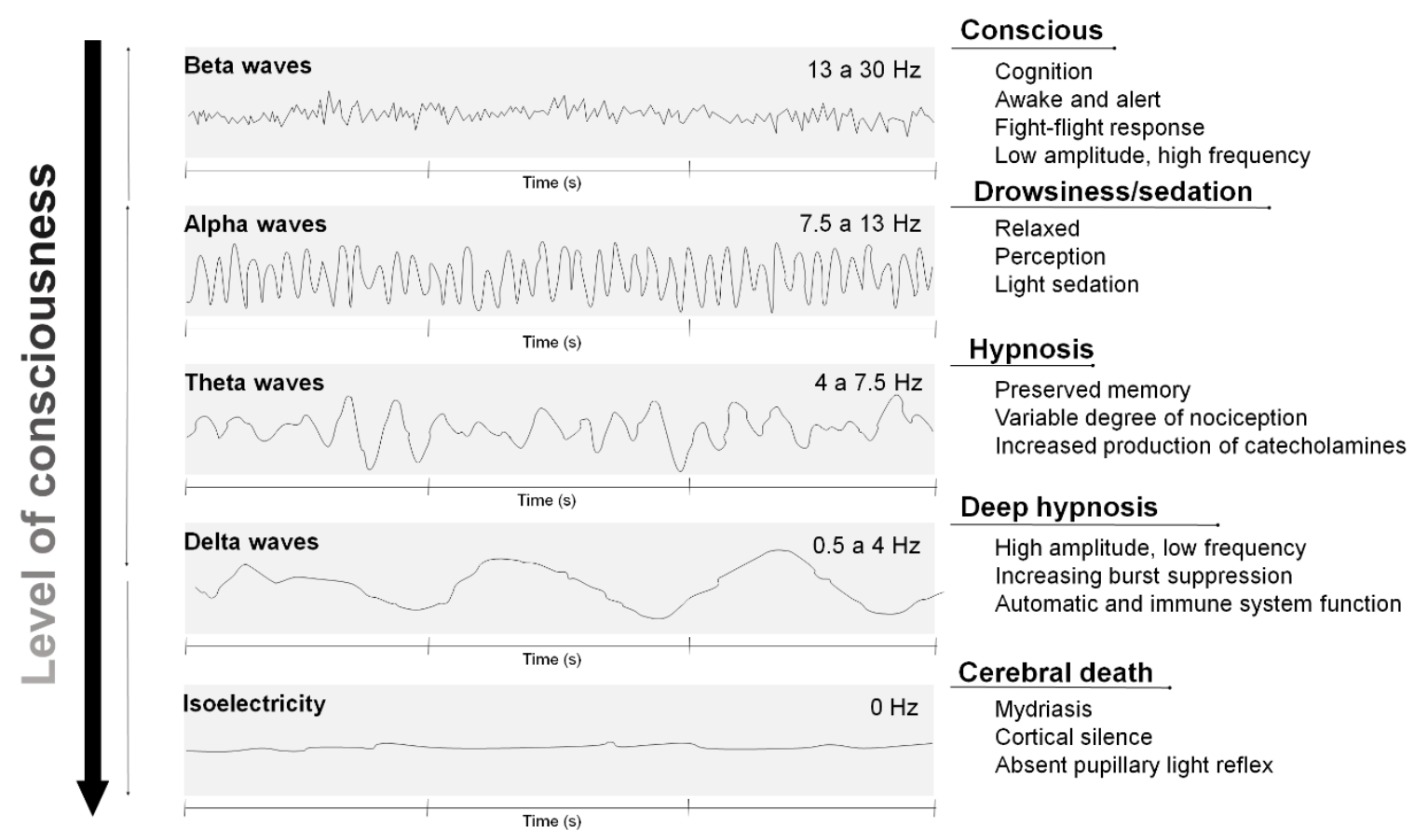

Figure 4 Electroencephalographic wave recordings in animals with different consciousness levels.

\subsection{Computed tomography}

Options developed in imaging studies for evaluating diverse diseases and lesions include computed tomography (CT). This is a precise technique to diagnose the extension and location of structures and possible lesions in several body cavities. This technique has been recently used to detect large animals' diseases, especially in the head area (Saunders and Van Bree 2003). The principal advantage of CT is its capacity to provide clear images of such regions as the nasal cavity and paranasal sinuses, free of interference from other anatomical structures. This method has been used in studies of large ruminants, as well as in dogs, horses, cats, and goats (Rycke et al 2003; Solano and Brawer 2004; Reetz et al 2006;
Shojaei et al 2008; El-Gendy and Alsafy, 2010; Alsafy et al 2013).

\subsection{Stunning equipment for river buffalos}

Mechanical stunning instruments, such as the penetrating captive bolt gun, may have critical technical difficulties that affect stunning quality in some species' stunning quality due to specific anatomical features (Gibson et al 2015b). Techniques shown to perform efficient stunning in sheep and pigs include applying an ultra-high pulsed current, although this method has rarely been employed in cattle (Robins et al 2014). On this topic, Zulkifli et al (2019) reported that stunning via electrical discharge produces only an insignificant increase in catecholamine and cortisol levels; 
the authors concluded that pain perception with this method could be much lower or even null.

The techniques and equipment used in slaughtering animals vary from country to country. The European Union (EU), for instance, banned slaughtering cattle with a captive bolt gun to the occipital area. EU regulations point out that the impact should be aimed at the forehead since a bullet discharged through the nape may not penetrate deeply enough to perform optimal stunning (Gregory 2008). The stunning methods authorized by the EU include penetrating captive bolt guns, percussion, electronarcosis, and exposure to carbon dioxide (European Union, 2009). However, as mentioned earlier, the buffalo presents significant anatomical differences that must be considered when selecting the best stunning technique and stunning site before slaughter (Mota-Rojas et al 2019a,b). The anatomical differences between cattle and river buffalo (Bubalus bubalis) heads are significant enough as captive bolt models, commonly utilized with cattle (Bos taurus), do not function adequately in buffaloes (Bubalus bubalis). As a result, it often fails to produce a total loss of consciousness or optimal stunning quality. This is due primarily to the buffalo deeper frontal sinuses, hide thickness and hardness of bony skull plates (Schwenk et al 2016). These findings in buffaloes led Gregory et al (2009) to recommend directing the so-called poll shot (discharge in the occipital area) to the depression just below the intercornual bulge and above the intersection of the nape ligament (Figure 5).

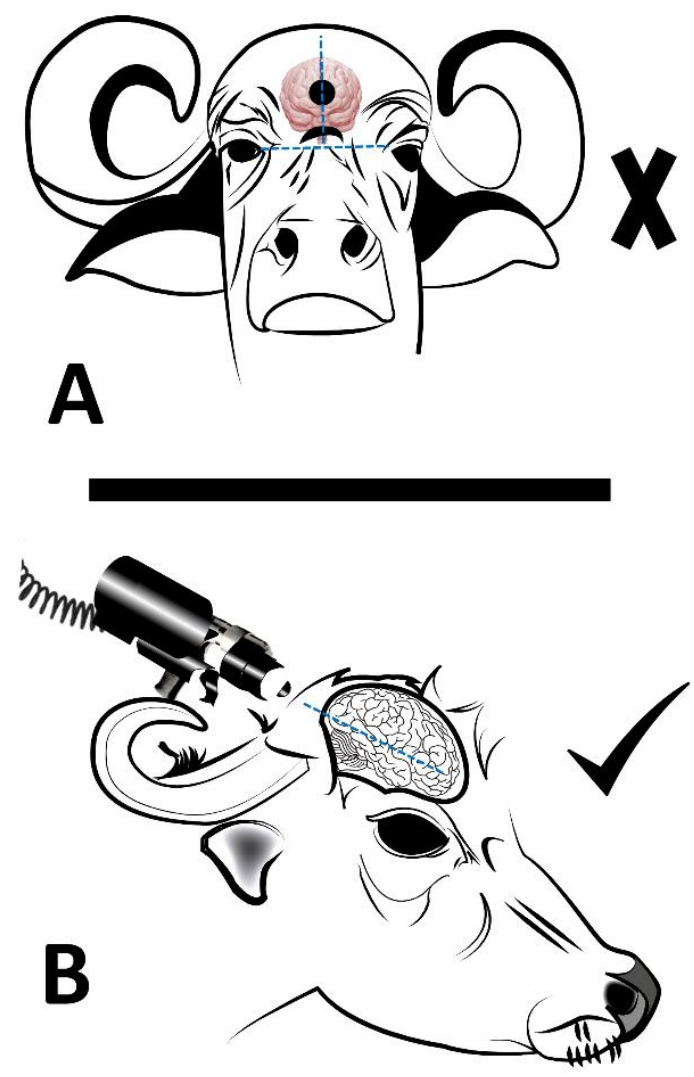

River buffalo (Bubalus bubalis)

Figure 5 A. The ideal stunning site for traditional bovines (genus Bos) is shown in diagram A, although this area of the head is not optimal for river buffalo due to this species cranium features described above. B. The recommended site for discharge application in buffaloes is the skull occipital region (poll position) towards the medulla oblongata (Diagrams courtesy of Ana María Duarte).

After analyzing a number of CT images, Alsafy et al (2013) concluded that the most suitable site to penetrate buffalos frontal bone is on an imaginary line joining medial points of the temporal regions, halfway between the central plane and the lateral head margin (Figure 5). When using a proper technique, the pistol is positioned at a right angle against the beast's skull so that the impact strikes the top part of the brain, directed towards medulla oblongata. When the discharge is applied accurately and powerfully at this particular site (in this case, with a captive bolt gun), it generates a rapid, abrupt movement of the head as a result of which the brain crashes inside the skull with an impact that triggers a sudden, massive increase of intracranial pressure cutting off all normal electrical activity, followed by a similarly 
sudden pressure drop. The damage to the animal nerves and blood vessels causes cerebral dysfunction or even destroy the brain. In either case, this technique blocks blood circulation, and the animal collapses (Anil 2012; Alsafy et al 2013).

Available evidence indicates that buffaloes' quality stunning is best achieved using captive bolt guns with a penetration capacity of at least $120 \mathrm{~mm}$, though there are cases in which not even $125-\mathrm{mm}$ guns act efficaciously. For this reason, it is important to take into account not only the critical characteristics of this species mentioned above but also specific features of individual animals, such as age, weight, sex, hide thickness, and skull dimensions, when choosing the stunning optimal method (Glardon et al 2018; Meichtry et al 2018).

\section{Final Considerations}

The growing amount of research on pre-slaughter stunning techniques generates evidence that different animal species require distinct methods and their application at a specific, optimal site for achieving complete desensitization as part of humane slaughtering procedures. This emphasizes the importance of training all the personnel involved in the slaughter process, from handling, through stunning, to death by exsanguination. Only in this way can abattoirs avoid making errors that jeopardize animal welfare by generating stimuli that trigger neurophysiological responses, translating into pain during slaughter. It is also necessary to select stunning methods to ensure that the animals will remain completely desensitized throughout the process. At the same time, it is important to use appropriate stunning equipment, with adequate maintenance and training the operators responsible for its use. Only by following these recommendations, it is possible to: (i) achieve the goal of preventing unnecessary pain and suffering to animals slaughtered for human consumption, and (ii) ensure good quality of death for the river buffalo and other species.

Finally, one of the main lessons learned in this regard is that river buffaloes taken to slaughter cannot be stunned in the same way as domestic cattle because of several significant characteristics of their skull anatomy compared to the crania of domestic cattle. These differences must be thoroughly understood and recognized, and optimal stunning techniques should be selected and applied in the abattoirs to ensure that the slaughtering process does not impose to the animals unnecessary pain and suffering.

\section{Conflict of Interest}

The authors declare that there are no conflict of interest with this work.

\section{Funding}

This research did not receive any financial support.

\section{References}

Alsafy MAM, El-Gendy SAA, El Sharaby AA (2013) Anatomic Reference for
Computed Tomography of Paranasal Sinuses and Their Communication in the Egyptian Buffalo (Bubalus bubalis). Anatomia, Histologia, Embryologia 42:220-231.

Anil MH, McKinstry JL (1992) The effectiveness of high frequency electrical stunning in pigs. Meat Science 31:481-491.

Anil M., Love S, Helps C., Harbour D. (2002) Potential for carcass contamination with brain tissue following stunning and slaughter in cattle and sheep. Food Control 13:431-436.

Anil MH, Austin A (2003) Bovine spongiform encephalopathy: a review of some factors that influence meat safety. FAO.

Anil M (2012) Effects of slaughter method on carcass and meat characteristics in the meat of cattle and sheep. 1-73.

Bosmans T, Doom M, Gasthuys F, Simoens P, Van Ham L, Polis L (2009) Perioperative pain: Physiology and pathophysiology. Vlaams Diergeneeskundig Tijdschrift 78:302-313.

Bourne S, Machado AG, Nagel SJ (2014) Basic Anatomy and Physiology of Pain Pathways. Neurosurgery Clinics of North America 25:629-638.

Cooley K (2015) Physiology of pain. In: Goldberg M Pain management for veterinary technicians and nurses. Wiley Blackwell, USA, pp. 30-41.

Covarrubias G (2013) El manejo del dolor agudo postoperatorio: una década de experiencias. Revista Mexicana de Anestesiología 36:179-182.

De Rycke LM, Saunders JH, Gielen IM, van Bree HJ, Simoens PJ (2003) Magnetic resonance imaging, computed tomography, and cross-sectional views of the anatomy of normal nasal cavities and paranasal sinuses in mesaticephalic dogs. American Journal of Veterinary Research 64:10931098.

De Oliveira JO de, Portella Junior CSA, Cohen CP (2016) Inflammatory mediators of neuropathic pain. Revista Dor 17:.

Dinakar P, Stillman AM (2016) Pathogenesis of Pain. Seminars in Pediatric Neurology 23:201-208.

Dong-Ho Y, Tae Wan K, Hee-jung C (2017) Pain in Animals: Anatomy, Physiology, and Behaviors. Journal of Veterinary Clinics 34:347-352.

El-Gendy S, Alsafy, M (2010) Nasal and Paranasal Sinuses of the Donkey: Gross anatomy and Computed Tomography. Journal of Veterinary Anatomy $3: 25-41$.

Ellison DL (2017) Physiology of Pain. Critical Care Nursing Clinics of North America 29:397-406.

European Food Safety Authority (EFSA) (2004) AHAW/04-027. Welfare aspects of stunning and killing methods. Scientific Report of the Scientific Panel for Animal Health and Welfare on a request from the Commission related to welfare aspects of animal stunning and killing methods (Question $N^{\circ}$ EFSA-Q-20.

European Union (2009) Council regulation (EC) No 1099/2009 of 24 September 2009 on the protection of animals at the time of killing. Official Journal of the European Union L 303, 1-30.

Farouk MM (2013) Advances in the industrial production of halal and kosher red meat. Meat Science 95:805-820.

Ferguson DM, Warner RD (2008) Have we underestimated the impact of preslaughter stress on meat quality in ruminants? Meat Science 80:12-19.

Fike K, Spire MF (2006) Transportation of Cattle. Veterinary Clinics of North America: Food Animal Practice 22:305-320.

Gibson TJ, Dadios N, Gregory NG (2015a) Effect of neck cut position on time to collapse in halal slaughtered cattle without stunning. Meat Science 110:310-314.

Gibson TJ, Mason CW, Spence JY, Barker H, Gregory NG (2015b) Factors Affecting Penetrating Captive Bolt Gun Performance. Journal of Applied Animal Welfare Science 18:222-238.

Glardon M, Schwenk BK, Riva F, von Holzen A, Ross GS, Kneubuehl PB, Stoffel HM (2018) Energy loss and impact of various stunning devices used for the slaughtering of water buffaloes. Meat Science 135:159-165.

Gregory NG (2008) Animal welfare at markets and during transport and slaughter. Meat Science 80:2-11. 
Gregory NG (2003) Animal welfare and meat science. CABI Publishing, USA.

Gregory NG, Wenzlawowicz M von, Holleben K von (2009) Blood in the respiratory tract during slaughter with and without stunning in cattle. Meat Science 82:13-16.

Guerrero-Legarreta I, Strappini CA, Mota-Rojas D, García I, Ramírez-Bribiesca E, Ghezzi M, Cruz-Monterrosa R.G, Lázaro de la Torre C, Mora-Medina P, Alarcón-Rojo AD (2019) Chapter 21. Antemortem handling and quality of river buffalo and cattle. In: I. Guerrero-Legarreta, F. Napolitano, D. MotaRojas and A. Orihuela (eds.). The river buffalo in the Americas. Second edition. BM Editores press. Mexico City. Mexico. pp. 1-889.

Guerrero-Legarreta I, Napolitano F, Cruz-Monterrosa RG, Mota-Rojas D, Mora-Medina P, Ramírez-Bribiesca E, Braghieri A (2020) River buffalo meat production and quality: sustainability, productivity, chemical composition and sensory properties. Journal of Buffalo Science 9: 159-169.

Hassel B, Dingledine R (2012) Glutamate and glutamate receptors. In: Brady, S.T., Siegel, G.J., Albers, R.W., Price DN. Basic neurochemistry, 8th edn. Elsevier, USA, pp. 342-366.

Hernández-Avalos I, Mota-Rojas D, Mora-Medina P, Casas AA, Lezama-García GK, Olmos HA (2019) Review of different methods used for clinical recognition and assessment of pain in dogs and cats. International Journal of Veterinary Science and Medicine 7:43-54.

Imlan JC, Kaka U, Goh Y-M, Idrus Z, Awad EA, Abubakar AA, Ahmad T, Nizamuddin HNQ, Sazili, AQ (2020) Effects of Slaughter Knife Sharpness on Blood Biochemical and Electroencephalogram Changes in Cattle. Animals 10:579.

Immonen K, Kauffman R., Schaefer D., Puolanne E (2000) Glycogen concentrations in bovine longissimus dorsi muscle. Meat Science 54:163167.

Irurueta M, Cadoppi A, Langman L, Grigioni G, Carduza E (2008) Effect of aging on the characteristics of meat from water buffalo grown in the Delta del Paraná region of Argentina. Meat Science 79:529-533.

Johnson C, Gibson T, Stafford K, Mellor D (2012) Pain perception at slaughter. Animal Welfare 21:113-122.

Johnson C, Mellor D, Hemsworth P, Fisher A (2015) A scientific comment on the welfare of domesticated ruminants slaughtered without stunning. New Zealand Veterinary Journal 63:58-65.

Kandeepan G, Mendiratta SK, Shukla V, Vishnuraj MR (2013) Processing characteristics of buffalo meat-a review. Journal of Meat Science and Technology 1:1-11.

Kata Cl, Rowland S, Goldberg ME (2015) Pain recognition in companion species, horses and livestock. In: Goldberg, M.E. Pain management for veterinary technicians and nurses. Wiley Blackwell. Wiley Blackwell, USA, pp. 15-29.

Kooi KA, Tucker RP, Marshal R. (1978) Fundamentals of electro encephalography, 2nd edn. Harper and Row, New York.

Kopf A, Patel N. (2010) Guide to pain management in low resource settings. International Association for the Study of Pain 15-17.

Lambooy E (1982) Electrical stunning of sheep. Meat Science 6:123-135.

Lamont LA, Tranquilli WJ, Grimm KA (2000) Physiology of Pain. Veterinary Clinics of North America: Small Animal Practice 30:703-728.

Landa L (2012) Pain in domestic animals and how to assess it: a review. Veterinární Medicína 57:185-192.

Lapitan RM, Del Barrio AN, Katsube O, Ban-Tokuda T, Orden EA, Robles AY, Fujihara T, Cruz LC, Homma H, Kana Y (2007) Comparison of carcass and meat characteristics of Brahman grade cattle (Bos indicus) and crossbred water buffalo (Bubalus bubalis). Animal Science Journal 78: 596-604.

Leung E (2015) Physiology of pain. In: Sackheim K. Pain management and palliative care. Springer, New York.

Lopes PSS, Campos ACP, Fonoff ET, Britto LRG, Pagano RL (2019) Motor cortex and pain control: exploring the descending relay analgesic pathways and spinal nociceptive neurons in healthy conscious rats. Behavioral and Brain Functions 15:5.
Lorenz MD, Coates JR, Kent M (2011) Handbook of veterinary neurology, 5th edn. Elsevier Health Sciences, USA.

McKune CM, Murrell JC, Nolan AM, White KL, Wright BD (2015) Nociception and pain. In: Grimm KA, Lamont LA, Tranquilli WJ, Greene SA, Robertson SA, (eds) Veterinary Anaesthesia and Analgesia. Wiley-Blackwell, USA.

Meichtry C, Glauser U, Glardon M, Rossd GS, Lechnere I, Kneubuehlc PB, Gaschod D, Spadavecchiaf C, von Rotza A, Stojiljkovica A, Stoffe HM (2018) Assessment of a specifically developed bullet casing gun for the stunning of water buffaloes. Meat Science 135:74-78.

Mota-Rojas D, Guerrero-Legarreta I, Trujillo OM (2010a) (Eds). Animal welfare and meat quality. 1st. ed. B.M. Editores. Mexico City, Mexico. pp. 1361.

Mota-Rojas D, Alarcón-Rojo A, Vazquez GG, Guerrero-Legarreta I (2010b) Dark cutting beef, mechanisms involved. In: Mota-Rojas, D., GuerreroLegarreta, I., Trujillo, O.M. (Eds). Animal welfare and meat quality. 1st. ed. B.M. Editores. Mexico City, Mexico. pp. 1-361.

Mota-Rojas D, Becerril-Herrera M, Alonso SM, Ramírez NR, Trujillo OM (2012) Effects of long distance transport and $\mathrm{CO}_{2}$ stunning on critical blood values. Meat Science 90: 893-898. doi:10.1016/j.meatsci.2011.11.027

Mota-Rojas D, Velarde A, Maris-Huertas S, Cajiao-Pachón MN (2016) (Eds). Animal Welfare, A Global Vision in Ibero-America, 3rd ed.; Elsevier: Barcelona, Spain, pp. 1-516.

Mota-Rojas D, Ghezzi MD, Rosmini MR, Thielo de la Vega L, HernándezÁvalos I, Cajiao-Pachón MN, Panim-Ciocca JR, Lezama-García K, Lemus-Flores C, Guerrero-Legarreta I (2019a) Chapter 19. Signs of sensitivity during death: Assessment of beef and buffalo meat quality. In: I. Guerrero-Legarreta, F. Napolitano, D. Mota-Rojas \& A. Orihuela (eds.). The river buffalo in the Americas. Second edition. BM Editores press. Mexico City, Mexico. pp. 1-889.

Mota-Rojas D, Strappini AC, Ghezzi DM, Hernández-Ávalos I, Rosmini MR, Miranda-Cortés AE, Casas-Alvarado A, Lezama-García K, Guerrero-Legarreta I, Panim-Ciocca JR, Thielo de la Vega L (2019b) Chapter 20. Quality of death in cattle and buffalo. In: I. Guerrero-Legarreta, F. Napolitano, D. Mota-Rojas \& A. Orihuela (eds.). The river buffalo in the Americas. Second edition. BM Editores press. Mexico City, Mexico. pp. 1-889.

Mota-Rojas D, Broom DM, Orihuela A, Velarde A, Napolitano F, AlonsoSpilsbury M (2020) Effects of human-animal relationship on animal productivity and welfare. Journal of Animal and Biometeorology 8: 196-205. doi.org/10.31893/jabb.20026

Muir W (2009) Physiopatology and Pathophysiology of pain. In: Handbook of veterinary pain management. Mosby Elsevier, USA, pp. 13-41.

Reetz JA, Mai W, Muravnick KB, Goldschmidt MH, Schwarz T (2006) Computed tomographic evaluation of anatomic and pathologic variations in the feline nasal septum and paranasal sinuses. Veterinary Radiology Ultrasound 47:321-327.

Reyes A, De La Cala Carcía F, Garutti I (2004) Dolor postoperatorio: analgesia multimodal. Patología del Aparato Locomotor 2:176-188.

Robins A, Pleiter H, Latter M, Phillips CJC (2014) The efficacy of pulsed ultrahigh current for the stunning of cattle prior to slaughter. Meat Science 96:1201-1209.

Saunders JH, Van Bree H (2003) Comparison of radiography and computed tomography for the diagnosis of canine nasal aspergillosis. Veterinary Radiology Ultrasound 44:414-419.

Schwenk BK, Lechner I, Ross SG, Gascho D, Kneubuehl BP, Glardon M, Stoffel $\mathrm{MH}$ (2016) Magnetic resonance imaging and computer tomography of brain lesions in water buffaloes and cattle stunned with handguns or captive bolts. Meat Science 113:35-40.

Shearer J (2018) Euthanasia of Cattle: Practical Considerations and Application. Animals 8:57.

Shojaei B, Nazem MN, Vosough D (2008) Anatomic Reference for Computed Tomography of the Paranasal Sinuses and Their Openings in the Rayini Goat. Iranian Journal of Veterinary Suegery 77-85.

Sneddon LU, Elwood RW, Adamo SA, Leach MC (2014) Defining and assessing animal pain. Animal Behaviour 97:201-212. 
Solano M, Brawer RS (2004) CT of the Equine Head: Technical Considerations, Anatomical Guide, and Selected Diseases. Clinical Techniques in Equine Practice 3:374-388.

Spanghero M, Gracco L, Valusso R, Piasentier E (2004) In vivo performance, slaughtering traits and meat quality of bovine (Italian Simmental) and buffalo (Italian Mediterranean) bulls. Livestock Production Science 91:129-141.

Tarrant PV (1990) Transportation of cattle by road. Applied Animal Behaviour Science 28:153-170.

Teke B, Akdag F, Ekiz B, Ugurlu M (2014) Effects of different lairage times after long distance transportation on carcass and meat quality characteristics of Hungarian Simmental bulls. Meat Science 96:224-229.
Terlouw C, Bourguet C, Deiss V (2016) Consciousness, unconsciousness and death in the context of slaughter. Part I. Neurobiological mechanisms underlying stunning and killing. Meat Science 118:133-146.

Walters E (2018) Defining pain and painful sentience in animals. Animal Sentience 3:1-14

Zegarra P (2007) Bases fisiológicas del dolor. Acta Médica Peruana 24:105108.

Zulkifli I, Wakiman Z, Sazili AQ, Goh YM, Jalila A, Zunita Z, Awad EA (2019) Effect of shackling, electrical stunning and halal slaughtering method on stress-linked hormones in broilers. South African Journal of Animal Science 49:598-603. 